\title{
How to Apply Advanced Statistical Analysis to Computational Economics: Methods and Insights
}

\author{
Malin Song ${ }^{1} \cdot$ Ron Fisher ${ }^{2}$ \\ Published online: 6 July 2018 \\ (c) Springer Science+Business Media, LLC, part of Springer Nature 2018
}

\begin{abstract}
The theme of this special volume concerns advanced statistical analysis. By mining meaningful and important information, advanced statistical analysis can bring new insights to many areas, such as the development of hospitals, the environment, biology, markets, industries, and general economic systems. The contribution of this special volume is to adopt an advanced parametric and nonparametric statistical approach for the exploration of environmental and health care issues in the context of computational economics. The authors have proposed varied methods of advanced statistical analysis combined with practical applications. In terms of theory, the authors suggest designs for advanced theoretical methods. With regard to the application of professional calculation methods to everyday life, the authors have offered useful guidance for future research. The authors have also conducted empirical research by using data from Chinese regions and analyzing specific conditions. In addition, they have conducted empirical analyses of particular issues such as those related to the environment. Although this special volume has provided some methods of advanced scientific analysis for existing problems, other techniques must be applied to everyday life in order to solve the severe difficulties that human beings face.
\end{abstract}

Keywords Advanced statistical analysis - Theoretical method - Calculation method · Empirical research $\cdot$ Practical application $\cdot$ Environment

Malin Song

songml@aufe.edu.cn

Ron Fisher

r.fisher@griffith.edu.au

1 School of Statistics and Applied Mathematics, Anhui University of Finance and Economics, Bengbu 233030, Anhui, People's Republic of China

2 Department of International Business and Asian Studies, Griffith Business School, Griffith University, Gold Coast campus, Southport, Parklands Drive, QLD 4222, Australia 


\section{Introduction and Context}

In the past decade, a significant increase has occurred in the amount of theoretical and practical work that relies on parametric and nonparametric statistical models in different economic fields. These fields include environmental management, health care problems, macroeconomics, financial markets, and resource sustainability. They also cover areas related to R\&D innovation, technical progress, transportation, and issues of economic growth, firm development, and performance evaluation. Advanced statistical analysis has been an important technique that sheds light on the development of hospitals, the environment, biology, markets, industries, and general economic systems. These analyses have brought new insights to the above areas by mining meaningful and important information. Such insights are particularly significant in terms of the increasingly severe environmental pollution and problems of resource constraints that have seriously affected the global economy's development and threatened the natural environment in which human beings live. The mismanagement of natural resources has caused, and continues to cause, increasing risks to human health. Environmental protection and the sustainable utilization of resources are important issues in an increasing number of countries.

In response to these severe challenges, this special volume (SV) focuses upon advanced statistical methods in order to restore and maintain environmental ecosystems and improve human health. These objectives are essential for sustainable societal development. In this Special Issue of Computational Economics, 16 studies present new contributions to the literature. These studies have a particular focus on the adoption of an advanced parametric and nonparametric statistical approach for the exploration of environmental and health care issues in the context of computational economics. Further, each study has a significant computational basis/procedure. The authors have proposed varied methods of advanced statistical analysis combined with practical applications such as the design of a low-carbon supply chain network, nonparametric regression, total interpretive structural modeling (TISM), the price-gap approach and welfare evaluation methods, covariate matching techniques, data envelopment analysis (DEA), simulation, the Markov-switching vector error correction model (MS-VECM), and the entropy method.

\section{Articles in this Special Volume}

The articles in this SV can be roughly divided into three types. The first mainly considers the design of theoretical methods. The second for the most part addresses the application of calculation methods. The third type predominantly deals with empirical research.

\subsection{The Design of Theoretical Methods}

The authors of the articles on the design of theoretical methods have creatively improved existing research procedures in order to address practical problems and thereby close the gaps in the literature. 
Kuo et al. (2017) calculate carbon footprints by using the greenhouse gas (GHG) emissions data based on carbon footprint standards. Production capacities and costs are also collected and then evaluated through the application of Pareto optimal solutions. In order to achieve the optimal solutions, a normal constraint method is used to formulate a mathematical model that meets two objectives: low-carbon emissions and low cost. Further, the authors design a low-carbon supply chain network. This design is a multi-objective decision-making problem that involves a trade-off between lowcarbon emissions and cost. A case study is also presented to demonstrate the predictive ability of the model. The result shows that it is possible to reduce carbon emissions and lower cost simultaneously.

Vinod and Viole (2017) present a fundamentally unique method of nonparametric regression using clusters, which the authors then test against classically established methods. With the help of a simulation using deterministic (DT) and stochastic (ST) regressor models, the authors compare two nonlinear regression estimation packages called "NNS" and "np". The result shows that NNS always provides an excellent fit as indicated by the coefficient of determination (R2) and has a slight overall advantage over np. Regression coefficients are sometimes regarded as approximations of partial derivatives, especially in social sciences. NNS alone has the ability to compute a range of partials evaluated at points within the sample and also out-of-sample. The authors conclude that NNS can provide a viable alternative to kernel-based nonparametric regressions without using bandwidths for smoothing.

The need for theory building has been at the center of many discussions about environmental supply chains in recent years. However, research does not typically consider methods that aim to generate theory. Current methods such as econometric or structural equation modeling face challenges related to the ways in which causality is established because of potential issues regarding cross-sectional data sets. In order to address this difficulty, Luo et al. (2017) suggest an approach based on total interpretive structural modeling (TISM). The authors use graph theory logic to synthesize expert interpretations in the form of a theoretical supply chain model. This method may prove to be an alternative to econometric-based or structural equation modeling. In this regard, the authors explore the drivers of low-carbon supply chains and the relationships within them. The study's limitations and the opportunities for future research are also discussed.

\subsection{The Application of Calculation Methods}

In the following studies, which apply professional calculation methods to everyday life, the authors have provided useful guidance for future research. The specifics of the calculation method applied in each study are described in detail below together with the method's specific practical application.

\subsection{The Data Envelopment Analysis Model}

DEA is a new field in operational research, management science, and mathematical economics. It comprises a quantitative analytical method for evaluating the relative 
effectiveness of comparable units of the same type, based on a number of input and output indicators using linear programming.

Zhan et al. (2017) focus on urban efficiency in terms of efficient, inclusive, spatially coordinated, and sustainable urbanization instead of urban size. Utilizing the 2015 data of the input and output index system in Shanghai's 17 districts, a pilot application of DEA for the measurement of regional urbanization efficiency is demonstrated. The input-oriented BBC model and output-oriented CCR model are then used for the assessment and efficiency analysis of decision-making units (DMUs), while the spatial pattern of relative urbanization efficiency is examined by means of a spatial autocorrelation model. The results reveal that 11 of Shanghai's 17 districts have DEA efficiency. Statically and dynamically, the southern districts' urbanization efficiency is higher than in the middle and northeastern districts.

Yu et al. (2017) use DEA-based linear programming technology to compare potential industrial gains, including potential economic and environmental gains, from the command-and-control and carbon emissions trading mechanisms. The authors conduct an empirical study containing a data set of 38 subindustries in China and covering 2006-2014. The empirical results show that the carbon emissions trading mechanism can produce more potential gains compared with the command-and-control mechanism.

\subsubsection{Simulation Model}

Simulation refers to the establishment of a model to determine key characteristics based on an original system, transaction, or process for experimentation or training. The model is systematized and formulated to simulate key features. Simulation is not a single technique but a method to solve problems. It can use various models to represent practical difficulties and verify which measures are effective at solving them.

Li et al. (2018) use a multi-agent system to design a transportation simulation system for clean-energy vehicles in a scenic area. Adopting two perspectives, namely the introduction of clean-energy electric vehicles with limited and unlimited funds, the authors investigate the optimal introduction scheme and the optimal traffic scheme. The objective is to efficiently solve two primary issues: low-carbon environmental protection and traffic congestion.

Using a platform provided by computational economics, Zhang et al. (2017) establish a simulation model of agents in artificial credit markets. Further, the authors simulate credit transactions regarding debt contracts between firms and banks for different types of projects in various supervisory environments. The results show that the total amount of loans granted by banks to relationship firms is always more than the total amount granted to non-relationship firms. Moreover, the relationship between enterprises and banks can ease the financial difficulties of small- and medium-sized firms.

\subsubsection{Other Calculation Methods}

Other methods of computational analysis mainly involve covariate-matching techniques, the alternative bootstrap Granger causality test, and the nonlinear MS-VECM. 
The authors of the relevant studies apply these scientific calculation methods to specific environments and obtain thought-provoking conclusions.

Deng et al. (2017) consider the effect of expressways on cultivated land. The authors use satellite remote-sensing images of cultivated land in the Shandong province of China to test whether the introduction of an expressway in 2005 affected the level of cultivated land in 2010 and the rate of change from 2005 to 2010 . Under the premise of considering various factors, controlling all of the covariates, and using recently developed covariate-matching techniques to estimate treatment effects, the results demonstrate that an expressway can certainly be described as positively affecting cultivated land changes.

The Chinese government is paying increasing attention to electricity consumption as part of its monitoring of the economy. Wang et al. (2017) test whether electricity consumption is an appropriate indicator. In this regard, the authors propose an alternative bootstrap Granger causality test that can capture the contemporaneous correlation of the term error in the vector autoregressive model, based on a seemingly unrelated regression estimator. Using a quarterly data set containing dynamic changes, the authors reinvestigate the relationship between electricity consumption and economic growth. The results show that a long-term relationship exists between the two variables and that electricity consumption can be treated as an indicator of the functioning of the economy. Indeed, a significant unidirectional Granger causality is found to run from gross domestic product (GDP) to electricity consumption. However, the causality relationship from electricity consumption to GDP is relatively weak. Thus, electricity consumption is a useful indicator to check the reliability of GDP data but caution is required when using electricity consumption to predict future economic activities in China.

The impact of foreign direct investment (FDI) on China's $\mathrm{CO}_{2}$ emissions is an important index for evaluating the effect of foreign investment policy. Pan et al. (2017) use the monthly data of $\mathrm{CO}_{2}$ emissions and FDI from January 1997 to December 2013 to analyze the regime states. In this regard, the authors switch probability and regime correlation between FDI and $\mathrm{CO}_{2}$ emissions with the help of the nonlinear MS-VECM. The results indicate that the influence of FDI on $\mathrm{CO}_{2}$ emissions illustrates the tworegime dynamic characteristics: FDI has played a stimulating role in promoting China's $\mathrm{CO}_{2}$ emissions during January 1997 to October 2003, while having an inhibiting role during November 2003 to December 2013. The duration of the inhibiting effect of FDI on $\mathrm{CO}_{2}$ emissions is longer, and the frequency is higher, than that of the stimulating effect. Thus, the overall influence of FDI on $\mathrm{CO}_{2}$ emissions during January 1997 to December 2013 is inhibitive, which means that FDI has contributed to $\mathrm{CO}_{2}$ emissions reduction.

\subsection{Empirical Research}

The authors of the empirical research studies have applied various methods of advanced statistical analysis to solve difficult issues such as cross subsidies for natural gas, urban efficiency, urban firefighting, logistics, consumption, the environment, and the urban-rural income gap. 
Solving the problem of residential cross subsidies for natural gas is a key and difficult point in terms of phasing out fossil fuel subsidies further in China. The government has implemented increases in block tariffs for residential natural gas in order to settle this issue. However, the relevant research is still very limited. Lin and Liu (2018) apply the price-gap approach and welfare evaluation methods to analyze the subsidies and the increasing block tariffs for residential natural gas in Henan province in 2013. The authors find that the subsidies have mainly benefited high-income groups. Residential natural gas subsidies lack fairness and efficiency, a situation that has for the most part resulted in an excessive gas volume in the first block in Henan Province. In addition, the authors design schemes of increasing block tariffs for residential natural gas and find that more blocks and larger gaps in gas prices between blocks can optimize subsidy redistribution and improve fairness and efficiency.

Liu and Jiao (2017) focus on the effects of cognitive factors and risk attitudes on fire mitigation behavior. The authors consider two cognitive factors, threat appraisal and coping appraisal, within the protection motivation theory (PMT) framework. They also examine three types of fire-risk mitigation behavior: maintenance and caution, structural building measures, and fire insurance policy. The empirical research then uses field survey data from three ancient Chinese areas. The results indicate that coping appraisal and risk attitudes are important variables in terms of risk mitigation behavior.

Ma et al. (2017) investigate income inequality between Chinese rural and urban residents during 1978-2014, based on rural/urban flow and accumulated income Gini coefficients. The authors also compare the general changes in trends in these Gini coefficients in terms of urbanization and, by decomposing the Gini ratios, the ratio of urban to rural average income. The results show that the Gini coefficient of income flow has an inverted U-shaped pattern, while the Gini coefficient of accumulated income decreases significantly in most years. In particular, the latter demonstrates a decreasing trend since China's economic reform and opening, with a time lag and fluctuation.

Lan and Tseng (2017) conduct quantitative research to explore the mutual relationships between metropolitan economic development and logistics development. The authors apply the entropy method to determine two sets of key indicators' weights objectively. They also use the method to construct an evaluation model for coordinated development in order to measure the coordinated development degree scientifically. The authors then conduct empirical studies of five Chinese metropolitan areas based on the measuring model.

By expanding an R\&D-based growth model and using empirical analysis, Zhao and Song (2017) discuss the optimal combination for the government to coordinate its $R \& D$ expenditure as productive public investment in various sectors. The authors also discuss the promotion of long-term economic growth by considering aspects of the capability for independent innovation, the developmental capability for basic knowledge, and the absorption capability for the required techniques.

Using the data from 16 municipalities in Anhui province in 2015, Chen et al. (2018) present quantitative research on the correlation between rural residents' living standards and rural community management service levels. The results show that road mileage per 10000 people, rural water-improvement profitability, and rural sanitarytoilet penetration have a decisive influence on the improvement of living standards in Anhui's rural areas. 


\section{Discussion}

The various papers presented in this SV have demonstrated numerous methods of advanced statistical analysis. These can solve the diverse problems that people face and thereby improve the living environment for humans and ensure sustainable societal development. In everyday life, we must confront many complex and exhaustive difficulties. Qualitative analysis alone is not enough to uncover the nature of a problem and provide effective targeted recommendations. Especially in recent years, human beings have encountered increasingly serious and severe challenges, thereby making it vital to find and implement improved ways of reducing and managing these problems in the short- and long-term future. In this context, methods of advanced statistical analysis can provide suitable solutions.

Environmental protection and the sustainable use of resources are important issues in a growing number of countries because of increasingly severe pollution and resource constraints. Moreover, the mismanagement of natural resources has caused, and continues to cause, increasing risks to human health. Research in such fields requires innovative methods. Thus, the combination of advanced scientific research methods and practical applications is a suitable approach. Indeed, methods of advanced scientific analysis can be applied to research in order to meet the constant challenges that face human society. This SV has good examples of such a research direction and can be roughly divided into three parts. First, with regard to theory, the authors propose designs for advanced theoretical methods. Second, with regard to the application of calculation methods, the authors provide useful guidance for future research. Third, with regard to empirical research, the authors use data from Chinese regions and conduct empirical analysis based on specific conditions. In addition, some authors empirically analyze specific issues such as those related to the environment. Each study in this SV has a significant computational basis/approach.

However, although this SV provides methods of advanced scientific analysis for a range of existing problems, other advanced techniques are needed for application to everyday life in order to solve the severe difficulties that human beings face. These difficulties include environmental management, health care issues, macroeconomics, financial markets, and resource sustainability.

Funding This includes authors providing information regarding sources of funding.

\section{Compliance with Ethical Standards}

Conflicts of interest Identifying potential conflicts of interest (financial or non-financial).

Ethical Approval The guest editors and contributors confirm that they have followed accepted principles of ethical and professional conduct in relation to this SV.

Informed consent Identifying potential informed consent.

Human and animal rights In the case of research involving human participants or a statement on welfare of animals if the research involved animals. The corresponding author of each article is prepared to collect 
documentation of compliance with ethical standards and send if requested during peer review or after publication.

\section{References}

Chen, D., Wang, L., Su, T., \& Zhang, Y. (2018). Canonical correlation analysis between residents' living standards and community management service levels in rural areas: An empirical analysis based on municipal data in Anhui province. Computational Economics. https://doi.org/10.1007/s10614-017-9 791-4.

Deng, X., Gibson, J., \& Jia, S. (2017). Does expressway consume more land of the agricultural production base of Shandong province? Computational Economics, 1-2, 1-24. https://doi.org/10.1007/s10614-0 17-9747-8.

Kuo, T.-C., Tseng, M.-L., \& Chang, P.-C. (2017). Design and analysis of supply chain networks with low carbon emissions. Computational Economics. https://doi.org/10.1007/s10614-017-9675-7.

Lan, S., \& Tseng, M.-L. (2017). Coordinated development of metropolitan logistics and economy toward sustainability. Computational Economics, 4, 1-26. https://doi.org/10.1007/s10614-017-9788-z.

Li, L., Liu, W., Xiao, L., Sun, H., \& Wang, S. (2018). Environmental protection in scenic areas: Traffic scheme for clean energy vehicles based on multi-agent. Computational Economics. https://doi.org/1 0.1007/s10614-017-9790-5.

Lin, B., \& Liu, C. (2018). Evaluating design of increasing block tariffs for residential natural gas in China: A case study of Henan province. Computational Economics, 1, 1-17. https://doi.org/10.1007/s10614 -017-9674-8.

Liu, T., \& Jiao, H. (2017). Insights into the effects of cognitive factors and risk attitudes on fire risk mitigation behavior. Computational Economics, 1, 1-20. https://doi.org/10.1007/s10614-017-9727-z.

Luo, Z., Dubey, R., Papadopoulos, T., Hazen, B., \& Roubaud, D. (2017). Explaining environmental sustainability in supply chains using graph theory approach. Computational Economics. https://doi.org/ 10.1007/s10614-017-9688-2.

Ma, X., Wang, F., Chen, J., \& Zhang, Y. (2017). The income gap between rural and urban residents in China: Since 1978. Computational Economics, 6, 1-19. https://doi.org/10.1007/s10614-017-9759-4.

Pan, X., Zhang, J., Li, C., Quan, R., \& Li, B. (2017). Exploring dynamic impact of foreign direct investment on China's $\mathrm{CO} 2$ emissions using Markov-switching vector error correction model. Computational Economics. https://doi.org/10.1007/s10614-017-9745-x.

Vinod, H., \& Viole, F. (2017). Nonparametric regression using clusters. Computational Economics, 95, 1-18. https://doi.org/10.1007/s10614-017-9713-5.

Wang, J., Zhao, J., \& Li, H. (2017). The electricity consumption and economic growth nexus in China: A bootstrap seemingly unrelated regression estimator approach. Computational Economics, 5, 1-17. ht tps://doi.org/10.1007/s10614-017-9709-1.

Yu, Y., Zhang, W., \& Zhang, N. (2017). The potential gains from carbon emissions trading in China's industrial sectors. Computational Economics. https://doi.org/10.1007/s10614-017-9724-2.

Zhan, J., Zhang, F., Jia, S., Chu, X., \& Li, Y. (2017). Spatial pattern of regional urbanization efficiency: An empirical study of Shanghai. Computational Economics, 9, 1-15. https://doi.org/10.1007/s10614-01 7-9744-y.

Zhang, Y., Zhang, W., Xiong, X., \& Liu, X. (2017). Credit rationing and the simulation of multi-bank credit market model: A computational economics approach. Computational Economics, 237, 1-24. https:// doi.org/10.1007/s10614-017-9726-0.

Zhao, Y., \& Song, X. (2017). How should the Chinese government invest R\&D funds: Enterprises or institutions? Computational Economics, 2, 1-24. https://doi.org/10.1007/s10614-017-9787-0. 